This report was prepared as an account of work sponsored by an agency of the United States Government. Neither the United States Government nor any agency thereof, nor any of their employees, makes any warranty, express or implied, or assumes any legal liability or responsibility for the accuracy, completeness, or usefulness of any information, apparatus, product, or process disclosed, or represents that its use would not infringe privately owned rights. Reference herein to any specific commercial product, process, or service by trade name, trademark, manufacturer, or otherwise does not necessarily constitute or imply its endorsement, recommendation, or favoring by the United States Government or any agency thereof. The views and opinions of authors expressed herein do not necessarily state or reflect those of the United States Government or any agency thereof.

\author{
DOE/CE/15362--T6 \\ DE93 $0+1939$
}

\title{
IMPROVED SOLVENTS FOR SEAWATER DESALINATION \\ (THE PURAQ PROCESS)
}

\author{
United States Department of Energy \\ Grant Number DE-FG01-88CE15362
}

Project Period: June 7, 1988 to June 6, 1991

FINAL REPORT

RECEI:

AOP 29898

THE PURAQ COMPAYY

111 Hannah's Road
Stamford, Connecticut 06903

OSTI

$$
203-322-3925
$$

Project Manager for the Department of Energy
Jack Aellen CE-521

$$
\text { Jack Aellen CE-521 }
$$

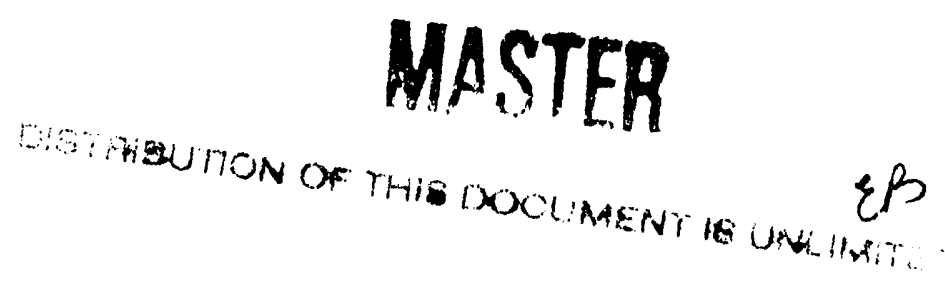


Table of contents

Page

I. INTRODUCTION - . . . . - . . . . . . . . 2

II. LABORATORY PROGRAM . . . . . . . . . . . . 3

III. CONClUSIONS. • . . . . . . . . . . . . . . 4

IV. "The Puraq Seawater Desalination Process - An Update" Reprint from DESALINATION 85(1992) 345-360 • after 4 


\section{INTRODUCTION}

The Puraq process for desalinating seawater is based on the solvent extraction of fresh water from seawater using specially-tailored liquid polymers with molecular weights of 3000 or less. The use of a polymeric solvent insures that the solubility of the solvent in the coexistent aqueous phases within the process will be essentially zero, as predicted by the Flory-Huggins theory of polymer solutions.

The technology, as well as the entire research effort to date, are described in the paper entitled "The Puraq Seawater Desalination Process - An Update" (DESALINATION 85(1992) 345-360, a reprint a which is attached to this report. This comprehensive paper, prepared as part of this project (DE-FG01-88CE15362), also incorporates the results of this project.

Prior to this project, the research results, particularly the phase relationships between water and polymer samples, obtained prior to this project, showed that the upper limit of polymer content in the recycle solvent stream could not exceed 92 per cent, thus unduly restricting the practical operating range in the solvent extraction process to 72 percent polymer for the water-rich solvent and 92 percent polymer for the recycled "water-lean" solvent. This represents an extraction capacity of 0.2960 pounds of water per pound of circulating solvent on a dry basis.

In spite of the extensive nature of this prior work, involving over two hundred candidate samples, there were strong indications that this restrictive upper limit of polymer content ( 92 per cent) could be exceeded by broadening the field of possible polymer compositions used in choosing a particular sample. These indications were based on the few published phase diagrams of analogous compounds. Also, the possibility of an artifact due to a faulted laboratory methodology merited consideration.

Should this limit, apparent or real, be raised to exceed 98 per cent, the extraction capacity would increase from 0.2960 pounds of water per pound of dry circulating solvent to 0.3685 . This increase has would an even greater effect on the projected cost of product water, decreasing the cost from $\$ 2.03$ to $\$ 1.08$ per thousand gallons, these figures resulting from detailed engineering and cost studies, performed as part of this project.

While both cost figures are considerably lower than the costs of desalinating seawater by current technologies (distillation or reverse osmosis), which is about six dollars per thousand gallons, nevertheless the improvement in projected costs for the puraq process was considered ample justification for this project. Widening the cost differential between desalinated water based on the puraq process and existing processes to this extent would further justify proceeding into the pilot-plant stage. 


\section{IABORATORY PROGRAY}

The experimental program consisted solely of the determination of the phase diag,ams of various terpolymer samples, synthesized according to purad specifications (molecular weight, co-monomer ratios and block configurations) by Ethox Chemicals of Greenville, sC. For purposes of comparison, a sample, designated as U-11755, retained from the previous research, was also included. U-11755 had been synthesized per specifications by BASF-Wyandotte.

In the previous research, phase points were determined solely by the cloud-point method, a very speedy procedure, permitting the screening of large numbers of samples in a given period of time. In this project, the equilibrium points were also measured by static equilibration of the coexistent aqueous and polymer phases in thermostatted water baths. This latter technique is very laborious and time-consuming, requiring frequent washings of the samples in work, along with clarification of both phases by gravity. Literally, several weeks of elapsed time are required for each measured point. of course, this problem was alleviated to a degree by the use of several water baths.

It was found at a relatively early stage that the upper limit of 92 per cent polymer for the aqueous system was an experimental artifact, and that all the previous phase diagrams were valid up to approximately 80 per cent polymer. For compositions in excess of 80 per cent polymer, phase composition points can only be determined with reliability by the method of thermostatted equilibration.

Subsequent work was directed at confirmation of this determination; after eight samples synthesized at Ethox Chemicals, no new samples were investigated.

The work led to the conclusion that the presence in the polymer of water-soluble components prevented the separation of water droplets when determining the cloud point with small amounts of water in the sample. A number of experiments confirmed this fact, including the addition of small quantities of polyethylene oxide, which is watersoluble, to a given sample and determining its effect on the appearance of a cloud-point, as well as the effect of prewashings on such cloud point determinations. This was reinforced by two measurements of distribution of molecular weights by gel permeation, confirming that the distribution "tails" were appreciable: e.g. that the molecular weight distribution in these polymers was relatively broad.

A number of measurements of "true" phase points indicated that for the majority of samples the difference in the temperatures of phase separation between compositions of 80 and 98 per cent was $15^{\circ} \mathrm{C}$ or less. This conclusion is most gignificant in reworking the data for previous samples. 


\section{CONCLUSIONS}

The fact that the Puraq solvents can be dewatered within the process to a recycle compositions of 98 per cent or more is significant in assessing the economics of the process relative to other methods of seawater desalination.

Engineering and cost studies have shown that this development will reduce the projected cost of desalinating seawater by this method of solvent extraction to slightly over one dollar per thousand gallons.

Associated with these studies was the preparation of a paper entitled "The Puraq Seawater Desalination Process - An Update" which appeared in the March issue of DESAIINATION 85(1992) 345-360. DESALINATION is a peer-review journal. A reprint of this paper is attached, and the contents of the paper are to be considered an integral part of this final report.

$$
\text { Refount remporeds }
$$




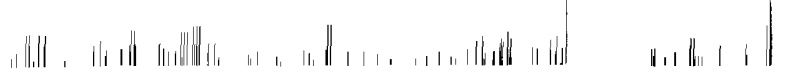
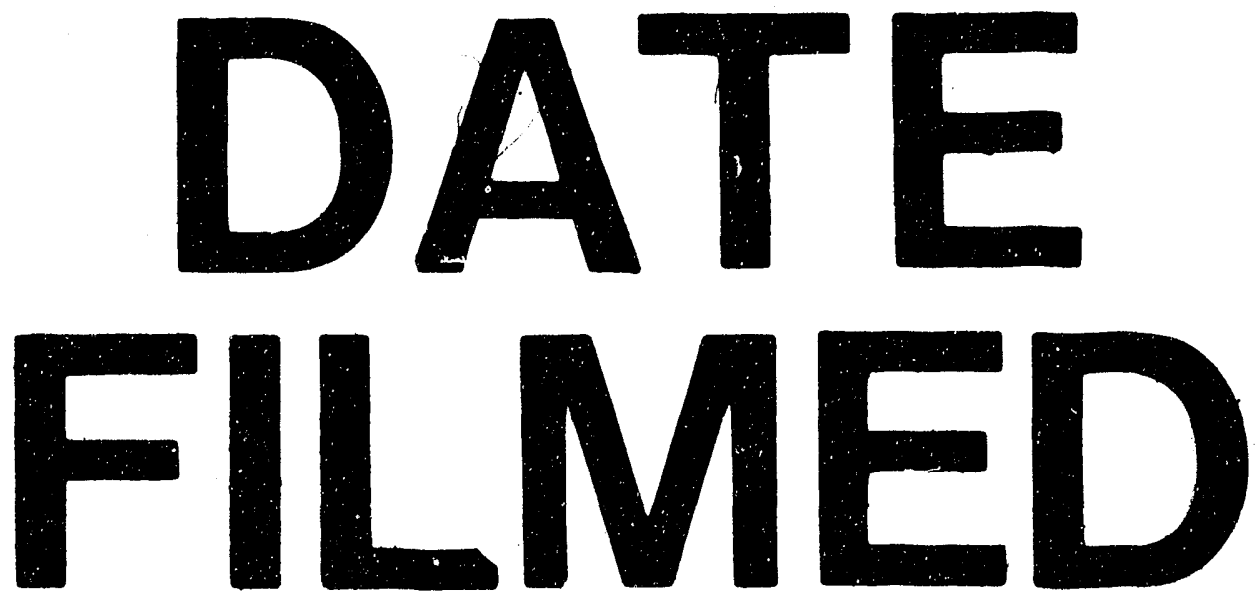

1
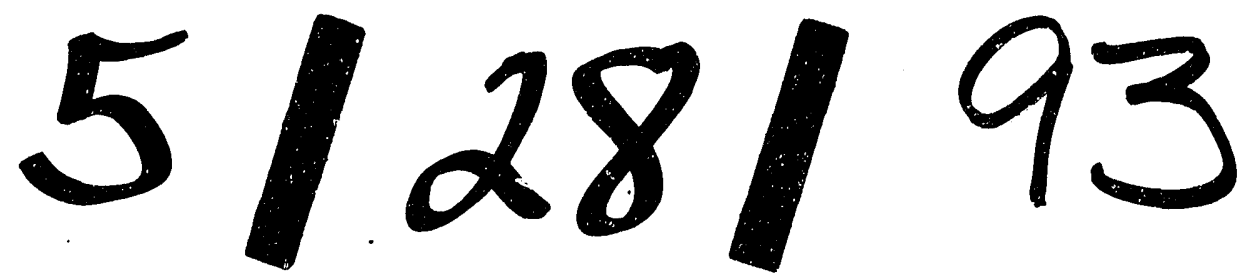
